\title{
Brief lullaby
}

\author{
A song from the stars.
}

\section{Val Nolan}

At first it is a whisper, a voice calling from the dark. The technician who records it considers it an aberration: a glitch, an unknown astronomical phenomenon or, at worst, a prank. Although she plays it to her colleagues for a day or two, no one expects the song to reappear. But it does.

It is a voice from another world, hundreds of thousands of years old if triangulated accurately. Meticulous investigation follows; months of study during which recordings of the song are bootlegged, leaked and then grudgingly confirmed. Governments issue statements. Papal edicts grapple with the implications. The Times proclaims four words that change our understanding of the Universe forever: WE ARE NOT ALONE.

It could not be kept a secret anyway, for as it strengthens the signal breaks through on ordinary radios, in the middle of the evening news or at a crucial moment in a drama. What panic ensues is soothed by the song itself, swelling to a dozen voices and then a hundred - an a capella polyphony out of which a soloist emerges sweet and soulful, lofting over his fellows. It is the music of a world bereft of instruments. Or more correctly, a world where voice itself is the instrument of choice. Who can forget their first time hearing how these hymns resolve from the sky's cacophony, those myriad cadences melting in and out of one another? "Where were you ...?" becomes a question around dinner tables, a way of introduction.

Science meanwhile strives to find the song's significance, seeking answers in its harmony or line. Some go mad, convinced we are meant to understand these grand, mercurial and vaguely sentimental themes as blueprints for the Universe itself, although most agree it is an accidental broadcast. The song is deemed to be the remnants of a transmission bubble, radio waves emanating from far beyond the Solar System and which now wash over what we thought of once as all creation. Only in the deaf season, when Earth slinks guiltily behind the Sun, do we lose the signal, although every spring we re-emerge from the shadow of the star and there it is: deepened, developed somehow. Its variations happier or sadder as the years go by, freed from its earlier constraints as we imagine its society must be.

Decades pass and powerful movements take hold. Sects emerge believing this to be the work of God. They propagate like signals in the dark and their teachings transcend traditional interpretations of Jewish or Christian or Muslim faith; they believe the choir of angels sings to all, and

A hybrid form is born and what began as wonder now becomes passé. The signal is just another broadcast, just another channel on the dial. The song itself is followed less and less.

That is until it starts to grow chaotic, its strength diminishing and its voices starting to go silent. Fanatics blame our own complacency and immolate themselves. Sociologists and radio astronomers struggle to explain the change. Analysis abounds. The leading theory holds that these developments record a period of conflict in the song's society. Soon the aliens resume their earlier celebrity and their operatic struggle takes hold of our imaginations. Their war is reported as though it were our own, interpretations of a language we have never learnt to understand.

In the course of five short years, static comes to dominate the otherworldly frequencies until the song begins to fade completely. The liveliness of earlier is spent. War has consumed their world. Sporadic, forlorn dirges sing to us of this, although these meek voices have the ear of only telescopes and satellites. They are relayed to great gatherings in the cities of the world, vigils that are held until the song dies out. Candlelight illuminates whole continents. A period of mourning is declared. The Times, with an eye to symmetry, reports on all of this in terms that emphasize our existential loneliness.

Mere histories or monuments cannot convey our grief. We

it is difficult to argue. Humanity finds purpose and solidarity as old philosophies and politics begin to wither. Green parties gain ground. The first and third worlds strive to close the gap. Climate change is stabilized and people start talking of Utopia, although this remains a long way off.

Beyond the reach of copyright, the alien signal airs on cheap wireless sets and on the Internet. A generation comes of age for whom it is the foremost influence. Songwriters and musicians begin to meld their styles to it, first sampling, then imitating, then incorporating freely. Musicologists become astronomers and physicists. Physicists write musicals and croon in deserted cabarets. Classical music, jazz, rock, pop and rap all listen and evolve. mourn the passing of these others with songs we sing ourselves, that amalgam we have made our own, that blend of human music and unearthly voice. Heartened for a hundred years, we might be all alone once more but we shall not forget. Our longdead cousins will survive in us, in this melodic dispatch towards the stars. Somewhere, a hundred or a hundred thousand years from now, we hope this message is received.

Val Nolan is a graduate of the Clarion writing programme at the University of California, San Diego. He currently teaches in the Department of English at National University of Ireland, Galway. Join the discussion of Futures in Nature at go.nature.com/QMAm2a 